\title{
Relative Stress-Optical Coefficients of Some National Bureau of Standards Optical Glasses ${ }^{1}$
}

\section{Roy M. Waxler and Albert Napolitano}

\begin{abstract}
The relative stress-optical coefficients of 27 optical glasses made at the National Bureau of Standards have been determined. The glasses were loaded in compression, and the amount of birefringence was measured with a polarimeter, using a quarter-wave plate compensator. The stress-optical coefficients determined for the crown glasses ranged between +2.95 and +1.82 brewsters. For the flint glasses, a regular variation of the stress-optical coefficient with weight percent of lead oxide was found with values ranging from +3.18 to -1.16 brewsters.
\end{abstract}

\section{Introduction}

The double refraction produced in isotropic solids by the application of stress was discovered by Brewster [1] ${ }^{2}$ who, incidentally, used glass for the greater part of his experiments. From Brewster's early work, the theory of photoelasticity has been developed [2] and is the basis of a recognized method of stress analysis for isotropic transparent solids.

For a given material, the relationship between the optical-path difference and the applied stress is

$$
r=C t d .
$$

$C$ is called the relative stress-optical coefficient and is characteristic of the type of glass under investigation. The above equation holds true for both compression and tension [3], and it is presumed to be valid up to the breaking stress of glass [4]. When $r$, the retardation, is expressed in angstroms; $t$, the stress, in bars; and $d$, the thickness, in millimeters, the resulting coefficient, $C$, is measured in brewsters.

The effect of the chemical composition of glass on the photoelastic effect was first investigated by Pockels [5], who came to the conclusion that an increase of lead oxide, or decrease of boric oxide, always lowers the relative stress-optical coefficient. In compression most glasses act as uniaxial negative crystals, but Pockels succeeded in observing a reversal of this effect for very heavy lead silicate glasses. The effect of the composition was more accurately studied by Filon [6] and Adams and Williamson [7], who reached the same general conclusions.

In more recent work, Vedam [8] measured the elastic and photoelastic properties of 18 optical glasses, and Schaefer and Nassenstein [9] made a very extensive study of these properties for 154 optical glasses produced by Schott \& Co. Unfortunately, the compositions of the glasses measured by Vedam are given only to a rough approximation, and these data are not mentioned in the paper of Schaefer and Nassenstein.

1 This work was sponsored by the Air Research and Development Command. U. S. Air Force under Contract No. AF 18 (600)-139.

2 Figures in brackets indicate the literature references at the end of this paper.
As the relative stress-optical coefficient relates the stress exerted upon a glass to the optical-path difference produced, a knowledge of this coefficient permits one to carry out a stress analysis of a glass specimen on the basis of the optical evidence of the existing strain. Furthermore, Lillie and Ritland [10] have shown that a knowledge of this coefficient for optical glasses is needed in order to develop fine annealing schedules that will keep the amount of birefringence within prescribed limits. In the course of developing annealing schedules for large optical elements, it was felt desirable to evaluate these coefficients for several glasses made at the Bureau. Because these are similar to commercial types of optical glasses, the results are offered for their potential interest to glass technologists.

\section{Optical System}

In most investigations of the relative stress-optical coefficient, the stressed specimen is placed in a 45 -deg position between crossed nicols. A Babinet compensator, also placed between the crossed nicols and at the same angle as the specimen, is used to measure the optical-path difference. However, the use of a quarter-wave plate as a compensator affords greater accuracy, and was used in this investigation [11]. With this arrangement, the polarizer is set at a 45-deg position with respect to the principal directions of the stressed specimen, and the elliptically polarized light emerging from the glass is restored to a linear polarization by a properly oriented quarter-wave plate. The quarter-wave plate and stressed glass in combination then have the same effect as an optically active material that rotates the plane of polarization of the incident light. The angular difference in the extinction positions of the analyzer may be noted if the analyzing nicol is mounted in a graduated circular scale. The amount of rotation is equal to one-half the phase angle, and may be used to measure the optical-path difference in the birefringent glass.

The optical arrangement and loading device used in this investigation are shown in figure 1 . The light source consisted of a laboratory sodium arc lamp. The light was collimated and filtered through a glass cell $15 \mathrm{~mm}$ in length that contained a 6 -percent solu- 


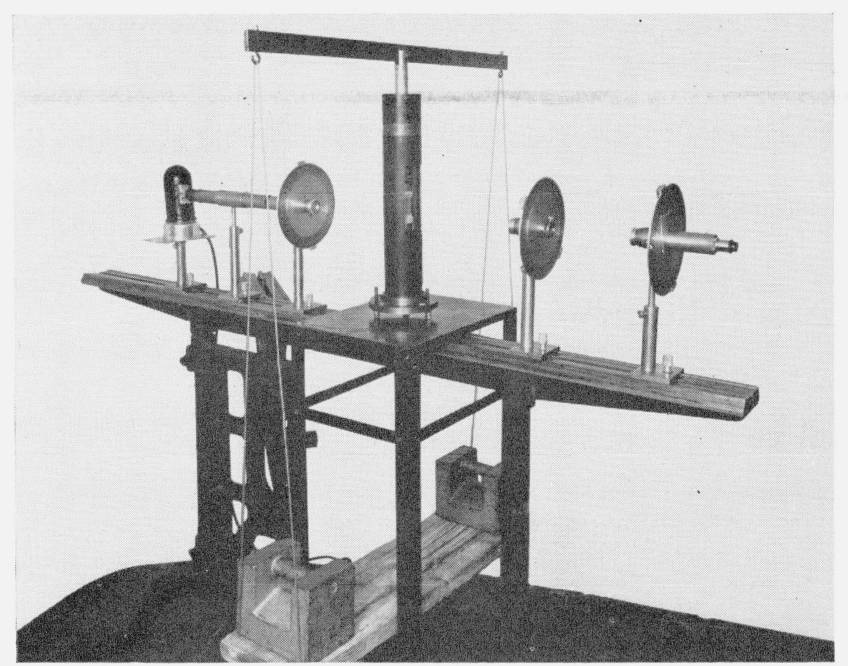

Figure 1. Optical system and loading device for determining the stress-optical coefficient of glasses.

tion of potassium dichromate. The wavelength was then taken as the mean of the two sodium $D$ lines, or $5893 \mathrm{~A}$.

The polarizer, quarter-wave plate, and analyzer were each mounted in a brass tube $3 \frac{1}{4} / 4$ in. long and $1^{1 / 4}$ in. in diameter. Nicol prisms were used for polarizer and analyzer, and the quarter-wave plate was a Babinet compensator adjusted to give the proper retardation.

The circles for measuring the amount of rotation were $8 \frac{1}{2} \mathrm{in}$. in diameter and graduated to $0.5 \mathrm{deg}$, with a vernier permitting readings to be made to $0.1 \mathrm{deg}$. A small telescope was mounted in the tube that held the analyzing nicol and was focused upon a 1/8-in.diameter hole, which formed a stop for the light beam as it emerged from the polarizer.

\section{Preparation of Samples}

The optical glasses tested are shown in table 1 , together with their chemical compositions as computed from the raw materials in the batch. Column 4 of table 1 identifies the glass according to optical type, refractive index, and Abbe valve [12].

These glasses were made in clay pots holding from 1,000 to $2,000 \mathrm{lb}$ of glass, depending on the type of glass. A 5-lb piece of high quality glass, ${ }^{3}$ which was representative of the type of glass under investigation, was selected from each melt. A test specimen was cut from each piece of glass and annealed. During heat treatment, each specimen was enclosed in a metal box in order to eliminate temperature gradients. The specimen was supported on small bits of refractory material so that it was not in contact with any part of the metal. The glasses were heated to a temperature about $20 \operatorname{deg} \mathrm{C}$ below the deformation point [13], held at this temperature for several hours, and then cooled at a rate of $1 \mathrm{deg} \mathrm{C} / \mathrm{hr}$ through the transformation region. Once through the transformation region, the glass was rapidly cooled to room temperature.

Each specimen of glass was annealed and then carefully ground to the shape of a rectangular block, the approximate dimensions being $3 \mathrm{~cm}$ by $3 \mathrm{~cm}$ by $10 \mathrm{~cm}$. Two opposite faces $3 \mathrm{~cm}$ by $10 \mathrm{~cm}$ were

${ }^{3}$ High-quality glass - seed free, striae free, having a nominal index of refraction, and a nominal dispersion.

TABLE 1. Relative stress-optical coefficient and compositions (computed from batch) of NBS optical glasses

\begin{tabular}{|c|c|c|c|c|c|c|c|c|c|c|c|c|c|c|c|}
\hline \multirow{2}{*}{ Specimen } & \multirow{2}{*}{$\begin{array}{c}C \text {, brewsters, } \\
\frac{10^{-13} \mathrm{~cm}^{2}}{\text { dyne }}\end{array}$} & \multirow{2}{*}{$\begin{array}{l}\text { Stand- } \\
\text { ard } \\
\text { error } \\
\text { of } C\end{array}$} & \multirow{2}{*}{ Glass type } & \multirow{2}{*}{ Melt } & \multicolumn{9}{|c|}{ Component oxides (weight \%) } & \multirow{2}{*}{ Other oxides } & \multirow{2}{*}{$\begin{array}{l}\text { Speci- } \\
\text { men }\end{array}$} \\
\hline & & & & & $\mathrm{SiO}_{2}$ & $\mathrm{PbO}$ & $\mathrm{BaO}$ & $\mathrm{B}_{2} \mathrm{O}_{3}$ & $\mathrm{Na}_{2} \mathrm{O}$ & $\mathrm{K}_{2} \mathrm{O}$ & $\mathrm{ZnO}$ & $\mathrm{As}_{2} \mathrm{O}_{3}$ & $\mathrm{Sb}_{2} \mathrm{O}_{3}$ & & \\
\hline $\begin{array}{ll}1 & \\
2 & \ldots \\
3 & \cdots \\
4 & \ldots \\
5 & \ldots\end{array}$ & $\begin{array}{l}\text { 2. } 93 \\
\text { 2. } 97 \\
\text { 3. } 18 \\
\text { 2. } 98 \\
\text { 2. } 77\end{array}$ & $\begin{array}{r}0.027 \\
.029 \\
.029 \\
.016 \\
.014\end{array}$ & $\begin{array}{l}\text { CF } 529 / 516 \ldots \\
\text { F } 5725 / 425 \\
\text { F } 5795 / 410 \ldots \\
\text { F } 605 / 380 \\
\text { F } 617 / 366\end{array}$ & $\begin{array}{l}8217 \\
7841 \\
7073\end{array}$ & $\begin{array}{l}65.4 \\
55.1 \\
53.1 \\
47.6 \\
45.6\end{array}$ & $\begin{array}{l}10.0 \\
31.7 \\
35.5 \\
40.9 \\
43.2\end{array}$ & $\begin{array}{l}0.2 \\
1.0 \\
0.6 \\
-\end{array}$ & \begin{tabular}{l}
$\cdots-$. \\
$\cdots \cdots$ \\
\hdashline$\cdots$ \\
$\cdots \cdots$
\end{tabular} & $\begin{array}{r}13.2 \\
5.0 \\
0.4 \\
2.2 \\
4.6\end{array}$ & $\begin{array}{l}5.6 \\
6.9 \\
9.6 \\
8.8 \\
6.1\end{array}$ & \begin{tabular}{c}
3.6 \\
$-\cdots$ \\
\hdashline-1. \\
-1
\end{tabular} & $\begin{array}{l}0.2 \\
.3 \\
.3 \\
.5 \\
.5\end{array}$ & \begin{tabular}{l}
1.8 \\
0.5 \\
\hdashline
\end{tabular} & & $\begin{array}{l}1 \\
2 \\
3 \\
4 \\
5 \\
5\end{array}$ \\
\hline $\begin{array}{l}6 \\
7 \\
8 \\
9 \\
10\end{array}$ & $\begin{array}{l}2.89 \\
2.65 \\
2.45 \\
2.18 \\
1.77\end{array}$ & $\begin{array}{l}.031 \\
.015 \\
.026 \\
.020 \\
.010\end{array}$ & $\begin{array}{l}\text { F } 620 / 362 \\
\text { F } 649 / 338 \\
\text { F } 666 / 324 \\
\text { F } 689 / 309 \\
\text { F } 720 / 293\end{array}$ & $\begin{array}{l}8622 \\
8865 \\
7686 \\
8652 \\
8968\end{array}$ & $\begin{array}{l}45.6 \\
41.2 \\
39.3 \\
37.0 \\
34.1\end{array}$ & $\begin{array}{l}45.5 \\
51.1 \\
54.4 \\
58.1 \\
62.4\end{array}$ & $\begin{array}{l}\cdots \\
\cdots \\
\cdots \cdots \\
\cdots \cdots\end{array}$ & $\begin{array}{l}\cdots \\
\cdots \\
\cdots \cdots \\
\cdots \cdots\end{array}$ & $\begin{array}{c}2.7 \\
0.7 \\
- \\
-\end{array}$ & $\begin{array}{l}5.7 \\
6.5 \\
6.0 \\
4.6 \\
3.2\end{array}$ & $\begin{array}{l}\cdots+. \\
\cdots \cdots \\
\cdots \cdots \\
\cdots\end{array}$ & $\begin{array}{l}.5 \\
.5 \\
.3 \\
.3 \\
.3\end{array}$ & \begin{tabular}{c}
$\cdots$ \\
$\cdots \cdots$ \\
\hdashline$\cdots$ \\
$\cdots \cdots$
\end{tabular} & & $\begin{array}{r}6 \\
7 \\
8 \\
9 \\
10\end{array}$ \\
\hline $\begin{array}{l}11 \\
12 \\
13 \\
14 \\
15\end{array}$ & $\begin{array}{r}1.33 \\
-1.16 \\
2.73 \\
2.56 \\
2.65\end{array}$ & $\begin{array}{l}.013 \\
.039 \\
.026 \\
.025 \\
.019\end{array}$ & $\begin{array}{l}\mathrm{F} 754 / 277 \\
\mathrm{~F} 920 / 211 \\
\mathrm{BaC} 541 / 599 \\
\mathrm{BaC} 5725 / 574 \\
\mathrm{BaC} 574 / 577\end{array}$ & $\begin{array}{r}8001 \\
\text { A2059 } \\
8700 \\
8702 \\
8573\end{array}$ & $\begin{array}{l}31.2 \\
20.0 \\
58.8 \\
45.2 \\
47.4\end{array}$ & $\begin{array}{l}66.2 \\
79.6 \\
\cdots \\
\cdots\end{array}$ & $\begin{array}{l}\text { 19. } 9 \\
28.7 \\
30.0\end{array}$ & $\begin{array}{l}3.8 \\
5.8 \\
4.9\end{array}$ & $\begin{array}{l}2.8 \\
1.8 \\
0.9\end{array}$ & $\begin{array}{r}2.3 \\
0.4 \\
10.3 \\
7.0 \\
7.0\end{array}$ & $\begin{array}{l}4.1 \\
7.5 \\
7.5\end{array}$ & $\begin{array}{l}.3 \\
.3 \\
.3 \\
.3\end{array}$ & \begin{tabular}{l}
$\cdots$ \\
\hdashline .7 \\
.5
\end{tabular} & $\begin{array}{l}\mathrm{Al}_{2} \mathrm{O}_{3} 3.0 \\
\mathrm{Al}_{2} \mathrm{O}_{3} 1.5\end{array}$ & $\begin{array}{l}11 \\
12 \\
13 \\
14 \\
15\end{array}$ \\
\hline $\begin{array}{l}16 \ldots \\
17 \\
18\end{array}$ & $\begin{array}{l}\text { 1. } 85 \\
\text { 1. } 83 \\
\text { 2. } 03\end{array}$ & $\begin{array}{l}.012 \\
.013 \\
.013\end{array}$ & $\begin{array}{l}\mathrm{BaC} 6109 / 572 \\
\mathrm{BaC} 611 / 588 \\
\mathrm{BaC} 617 / 550\end{array}$ & $\begin{array}{l}8462 \\
8621 \\
8890\end{array}$ & $\begin{array}{l}38.2 \\
38.3 \\
37.3\end{array}$ & $\begin{array}{r}0.2 \\
.2 \\
1.4\end{array}$ & $\begin{array}{l}42.9 \\
42.6 \\
44.8\end{array}$ & $\begin{array}{r}6.7 \\
10.7 \\
4.4\end{array}$ & 2 & 0.4 & 4. 2 & $\begin{array}{l}.4 \\
.4 \\
.3\end{array}$ & $\begin{array}{l}.2 \\
.2 \\
.7\end{array}$ & $\begin{array}{l}\mathrm{Al}_{2} \mathrm{O}_{3} 4.9, \mathrm{CaO} 2.3 \\
\mathrm{CaO} 4.5, \mathrm{Al}_{2} \mathrm{O}_{3} 3.1 \\
\mathrm{Al}_{2} \mathrm{O}_{3} 4.9\end{array}$ & $\begin{array}{l}16 \\
17 \\
18\end{array}$ \\
\hline 19 & 1.82 & .018 & $\mathrm{BaC} 620 / 600$ & 7903 & 37.8 & $\ldots$ & 44. 2 & 11.3 & $\ldots$ & $\ldots . .$. & $\ldots$ & 3 & .2 & $\{\mathrm{CaO} 3.6, \mathrm{BeO} 2.3$, & 19 \\
\hline $\begin{array}{l}20 \\
21 \\
22 \\
23\end{array}$ & $\begin{array}{l}\text { 2. } 95 \\
\text { 2. 35 } \\
\text { 2. } 84 \\
\text { 2. } 78\end{array}$ & $\begin{array}{l}.022 \\
.026 \\
.037 \\
.016\end{array}$ & $\begin{array}{l}\text { BaF } 584 / 460 \\
\text { BaF 588/534 } \\
\text { BaF } 605 / 436 \\
\text { LC } 512 / 605\end{array}$ & $\begin{array}{l}8610 \\
8691\end{array}$ & $\begin{array}{l}49.8 \\
45.8 \\
45.7 \\
71.9\end{array}$ & $\begin{array}{r}18.8 \\
5.6 \\
23.3\end{array}$ & $\begin{array}{l}13.4 \\
28.0 \\
14.3\end{array}$ & 4. 4 & $\begin{array}{l}1.5 \\
2.3\end{array}$ & $\begin{array}{l}8.2 \\
6.0 \\
8.2 \\
5.0\end{array}$ & $\begin{array}{l}7.8 \\
7.5 \\
8.1\end{array}$ & $\begin{array}{l}.5 \\
.4 \\
.4\end{array}$ & $\cdots$ & ( & $\begin{array}{l}20 \\
21 \\
22 \\
23\end{array}$ \\
\hline $24 \ldots$ & 2. 76 & .016 & LC $523 / 586 \ldots$ & 8695 & 70.2 & $\ldots$ & $\ldots$ & 1.5 & 14.0 & 2.5 & $\ldots$ & $\ldots$ & 1.2 & $\left\{\begin{array}{c}\mathrm{CaO} 9.4, \mathrm{Cl} \\
\mathrm{SO}_{3} 0.5 .\end{array}\right.$ & 24 \\
\hline $25 \ldots$ & 2. 66 & .016 & LC $528 / 580 \ldots$ & 7617 & 68.3 & .... & .... & 1.5 & 14.0 & 2.5 & -... & -... & 1.2 & 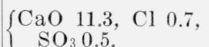 & 25 \\
\hline $\begin{array}{l}26 \\
27\end{array}$ & $\begin{array}{l}2.75 \\
2.81\end{array}$ & $\begin{array}{l}.021 \\
.019\end{array}$ & $\begin{array}{l}\text { BSC } 511 / 635 \\
\text { BSC } 517 / 645 \ldots\end{array}$ & $\begin{array}{l}8713 \\
8843\end{array}$ & $\begin{array}{l}68.8 \\
66.3\end{array}$ & 0.5 & -... & $\begin{array}{r}8.5 \\
12.5\end{array}$ & $\begin{array}{l}7.8 \\
7.5\end{array}$ & $\begin{array}{l}14.7 \\
12.8\end{array}$ & $\cdots$ & $\begin{array}{r}.2 \\
.4\end{array}$ & 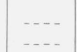 & & $\begin{array}{l}26 \\
27\end{array}$ \\
\hline
\end{tabular}


polished, in order to transmit the light beam. Attention is called to the fact that the length of the specimen was made three times its width to avoid end effects [14].

After annealing, grinding, and polishing, the residual strain was measured. An optical path difference of no more than 2 or $3 \mathrm{m \mu} / \mathrm{cm}$ was observed. This nominal residual strain was presumed to remain constant during the tests. A zero correction was unnecessary as the relative stress-optical coefficient is determined from differences in applied load.

\section{Method of Loading}

The load was applied by means of a vertical shaft which supported a horizontal yoke, and suspended loading platform, as shown in figure 2 . The shaft and the two vertical guides were machine polished to insure a smooth and close fit, thus allowing only vertical motion to the shaft. A $3 / 8$-in.-diameter steel ball was seated in the center of a metal disk at both ends of the glass specimen. Seats were also made on the end of the shaft and the bottom steel support to accommodate the ball. When this assembly was inserted under the shaft, the axis of the shaft and glass coincided. By taping the glass near both ends, the specimen was centrally located within each disk. A light film of oil was placed at the glass and metal interface. This method has been described in a

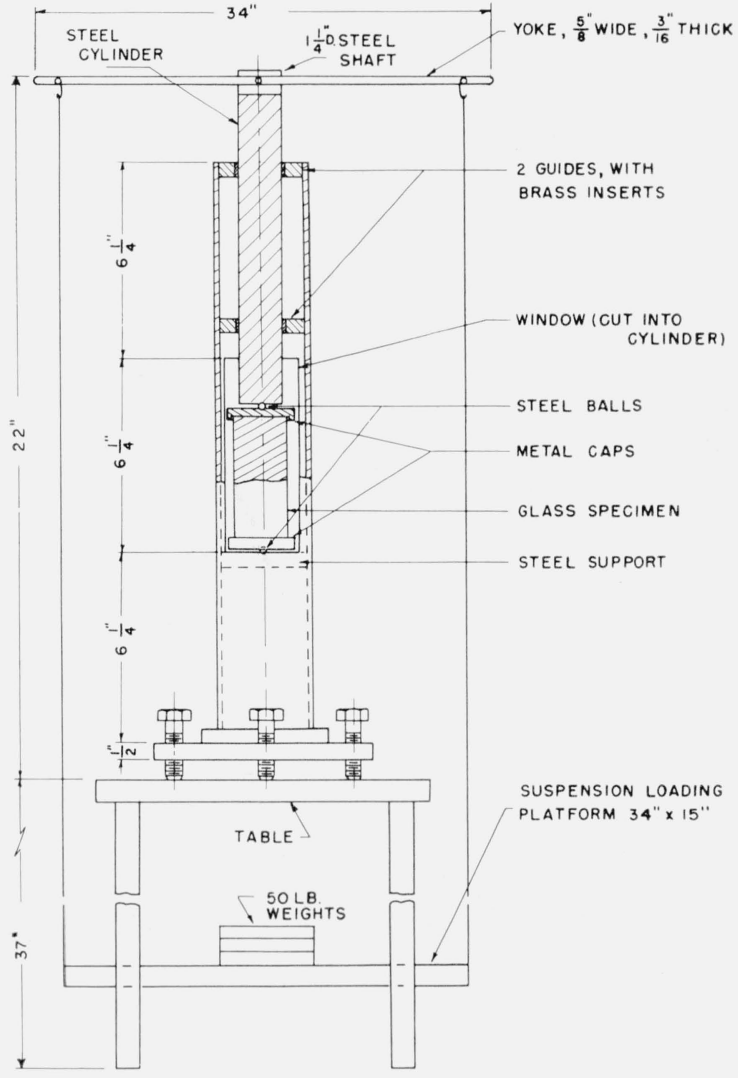

Figure 2. Loading apparatus. previous paper [15], and it has proved quite satisfactory in producing a uniform stress. ${ }^{4}$

By means of leveling screws and a bubble level, the steel cylinder was adjusted into a vertical position, making it possible to rest the glass on a horizontal surface. The glass, being then in vertical position, could be placed in alinement with the direction of force created by the load. This line of force established the directions of the planes of polarization of light transmitted by the glass.

To apply the stress, 50-lb weights were supplied by the Mass and Scale Section of the Bureau. Upon calibrating these weights, it was found that they were accurate to within $0.007 \mathrm{lb}$, which was felt to be more than satisfactory because it was desired to determine the values of the stress-optical coefficients only to three significant figures.

\section{Procedure}

Each part of the optical train was adjusted so as to be perpendicular to the light path. This was accomplished by noting the reflection of light from each surface and making certain that the reflected beam of light coincided with the incident beam.

It was necessary also to have some base point on the graduated circle of the analyzer in order to orient the polarizer and quarter-w ave plate in 45 deg positions relative to the optic axes of the stressed glass. For this reason each specimen was loaded to $300 \mathrm{lb}$, and one of the optic axes was found by alternately rotating the polarizer and analyzer until a position of minimum intensity was reached. Extinction positions noted on the analyzer and polarizer could be reproduced to within $\pm 0.1 \mathrm{deg}$ of arc. Both axes were found in this manner, and a point midway between the two, as noted on the analyzer, was used as a base point for subsequent settings of the polarizer and quarter-wave plate. These elements then could be set to within $\pm 0.1 \mathrm{deg}$. This method was falt to be satisfactory, considering the magnitude of errors that might possibly be introduced by missettings [11].

The birefringence produced in stressed glass may be used to ascertain the uniformity of stress distribution, as well as its magnitude. Before making any measurements, several of the specimens were loaded and examined in a broad beam of white light between sheets of Polaroid in a crossed position. With the aid of a sensitive red-tint plate it could be seen that the whole central portion of the specimen had a uniform color.

In making measurements, the glass was weighted with a tare consisting of the steel shaft, yoke, and loading platform, and the extinction position of the analyzer was noted. Then a 50-lb weight w as added to the loading platform, and another extinction position noted. This process was repeated with 50 -lb weight increments until the maximum load was $300 \mathrm{lb}$. Waiting about $5 \mathrm{~min}$ before readings,

${ }^{4}$ With this method of loading, the vertical thrust passes exactly centrally through the block, and it is a well-known principle in mechanies that at a sufficient distance from the point of application of a load, the stress system depends only on the statical resultant of the load. 
the measurements were made in a darkened room so that the eve might be more sensitive to the intensity of the light beam viewed through the analyzer. The room was kept at a temperature of approximately $20^{\circ} \mathrm{C}$.

It was noted that a specimen would exhibit the same extinction position before and after the application of the 300-lb load. This was checked with several glasses, and no difference could be detected outside the error of the instrument.

In investigating a particular specimen, 10 measurements were made for each extinction position, making a total of 70 measurements.

\section{Results and Discussion}

The results of this investigation are given in table 1, which lists the values of the relative stressoptical coefficient and their standard errors. The values were determined from the measurements in the following manner.

If $\Delta w$ is the load increment in pounds, $d$ the thickness of the specimen in inches, and $b$ the width of the specimen in inches, we obtain

$$
r=\frac{1.752 C(\Delta w) d}{b d}
$$

where $r$ is the retardation in angstroms, and $C$ is the stress-optical coefficient in brewsters. The number, 1.752 , is a conversion factor for the units employed.

As discussed in section 2 , the retardation can also be expressed in terms of the angle through which the plane of polarization is rotated. The equation reads

$$
r=\frac{2(\Delta y) \lambda}{360.0}
$$

where $2 \Delta y$ is twice the rotation of the analyzer in degrees of arc and $\lambda$ is the wavelength of the light in angstroms.

The angular rotation of the plane-polarized light is a linear function of the applied load. The increment in angular rotation can be represented by the relation

$$
\Delta y=B(\Delta w)
$$

from eq (2) and (3), where $B$ is the slope of the straight line. It is appropriate to consider increments rather than accumulated total rotations, because, for each glass, the measurements corresponding to the various loads were all made on the same specimen, and consequently a cumulative effect may be expected in the errors of the accumulated rotation values. Errors in the optical measurements, on the other hand, are effectively reduced through the compensating effect of averaging 10 duplicate measurements at each load. A detailed statistical analysis shows that this reduced error in the optical measurement is negligible in comparison with the experi- mental errors due to the method of applying the load. Under these conditions, the correct leastsquares estimate of slope $B$ is obtained by averaging the five values of $\Delta y$, corresponding to the five consecutive 50-lb increments. From these five values it is also possible to calculate the precision of the evaluated slope. Each slope estimate was converted into a $C$ value, expressed in brewsters, and the standard error of $C$ was derived from that of the corresponding slope. Table 1 lists the $C$ values and their standard errors. A measure of uncertainty (95\% confidence interval) can be obtained for these values by considering the interval $C \pm(2.8$ times standard error).

As shown in table 1 most of the glasses studied in this investigation have values of stress-optical coefficient that are fairly close together, ranging from 2 to 3 brewsters. Two glasses in table 1 , Nos. 16 and 17, vary only slightly in composition, and may be seen to have almost the same value of stress-optical coefficient, 1.85 and 1.82 brewsters, respectively.

Because optical glasses are in general made up of so many different chemical components, it is difficult to correlate changes in physical properties with a particular constituent. As the series of flint glasses consists principally of silica and lead oxide, it is interesting to note that, when the values of the stress-optical coefficient are plotted against percentage of lead oxide, a regular variation is indicated. This confirms the observations of other investigators, notably Pockels ${ }^{5}[5]$ and Filon [6], whose results are shown in figure 3, together with the values obtained in this investigation. Furthermore, flint glass F920/211 is seen to depart from the general rule that glass in compression acts as a uniaxial negative crystal.

${ }^{5}$ Pockels determined the absolute changes in the refractive index of a stressed glass for light polarized, parallel, and perpendicular to the direction of force, and expressed his results by the coefficients $p / v$ and $q / v$. With knowledge of these values, the relative stress-optical coefficient, $C$, may be calculated for purposes of comparison. This was done by Filon, and his results are shown in figure 3. Adams and Williamson also calculated $C$ for Pockels' glasses and found that the results showed good agreement with their own determinations.

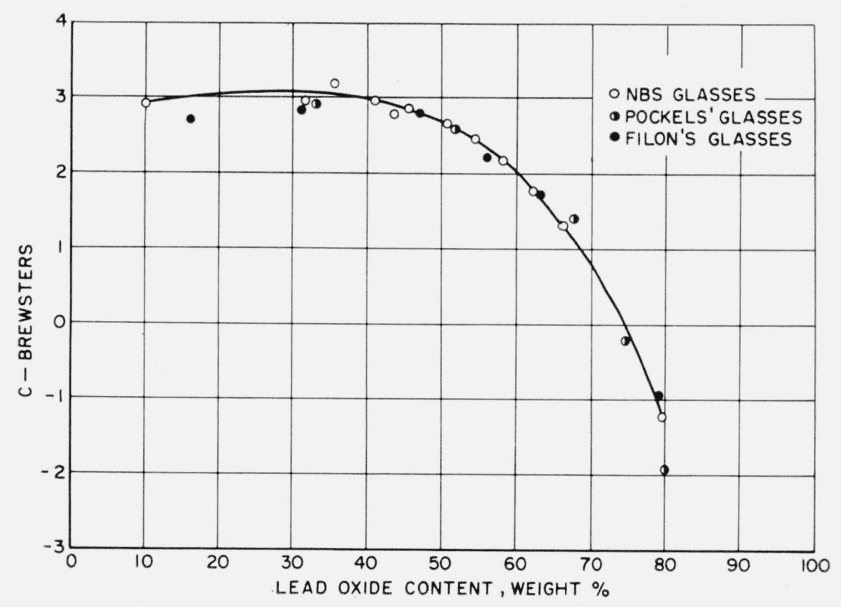

FiguRE 3. Variation of the stress-optical coefficient with lead oxide content in flint glasses. 
Pockels [5] and Filon [6] also concluded that lowering the amount of $\mathrm{B}_{2} \mathrm{O}_{3}$ in a series of glasses decreased the relative stress-optical coefficient. It was impossible to verify this from the results of the present investigation because the glasses studied here were multicomponent and contained comparatively little boric oxide, the amount being, at most, only 12.5 percent.

The authors are deeply appreciative of the statistical analysis of the data by John Mandel and Mary N. Steel. They are also grateful to Joseph M. Nivert, Jr., for preparation of the glass specimens for this work.

\section{References}

[1] Sir David Brewster, Phil. Trans. (105), 60 (1815); Phil. Trans. (106), 156 (1816); Trans. Roy. Soc. Edinburgh 8, 369 (1818).

[2] E. G. Coker and L. N. G. Filon, Treatise on photo-elasticity (Cambridge University Press, London, 1931).
[3] S. R. Savur, Phil. Mag. 50, 453 (1925).

[4] L. N. G. Filon, A manual of photo-elasticity for engineers, p. 33-36. (Cambridge University Press, London, 1936).

[5] F. Pockels, physik Z. 2, 693 (1901); Ann. Physik \%, 745 $(1902) ; \mathbf{9}, 220(1902) ; 11,651(1903)$.

[6] L. N. G. Filon, Proc. Roy. Soc. 79, 440 (1907); 83, 572 (1910).

[7] L. H. Adams and E. D. Williamson, J. Wash. Acad. 9, 609 (1919)

[8] K. Vedam, Proc. Indian Acad. Sci. [A] 31, 450 (1950).

[9] Clemens Schaefer und Heinrich Nassenstein, Z., Naturforsch. [A] 8, 90 (1953).

[10] H. R. Lillie and H. N. Ritland, J. Am. Cer. Soc. 37, 466 (1954).

[11] R. W. Goranson and L. H. Adams, J. Franklin Inst. 216, 475 (1933).

[12] ASTM standards on glass and glass products ASTM designation: C 162-52, page 68 (April 1955).

[13] F. W. Glaze, Optical glass at the National Bureau of Standards, NBS Circ. 469

[14] M. M. Frocht, Photo-elasticity, vol. II, p. 30 (John Wiley \& Sons, Inc., New York, N. Y., 1948).

[15] R. M. Waxler, Glass Ind. 34, 258 (1953).

Washington, January 31, 1957. 